\title{
ISU-ISU BERKAITAN PLURALISME AGAMA DI MALAYSIA: SUATU ANALISIS AWAL
}

\author{
Ahmad Mohamad ${ }^{1, *}$, Alwani Ghazali ${ }^{1}$, Wan Zailan Kamaruddin Wan Ali $^{1}$ \\ ${ }^{1}$ Jabatan Akidah dan Pemikiran Islam, Akademi Pengajian Islam Universiti Malaya, 50603 Kuala Lumpur, \\ MALAYSIA.
}

\begin{abstract}
Numerous new ideas are emerging as a result of post-modernism, along with various ideologies such as religious pluralism. Many countries, including Malaysia, has seen the dissemination of the religious pluralism ideology. Religious pluralism is extremely hazardous since it is an ideological attack that seeks to change one's ideas by attacking one's reasoning. In fact, it leads to confusion over religious understanding and manipulates the nature of religious diversity. As a result, the subject is seen as a threat to a person's real views and values, particularly for Muslims. In Malaysia, there are a number of difficulties that are said to be linked to the growth of religious diversity. The objective of this study is to identify the emerging issues associated with religious pluralism in Malaysia. The second objective of this study is to conduct a preliminary analysis of the difficulties that occur as a result of religious pluralism in Malaysia by comparing them to the policies that are brought about by religious pluralism. This research will employ qualitative research methodologies and will place a greater emphasis on data collecting based on literature reviews. This article concludes that the religious pluralism has ideological relevance in many of the issues that arise in Malaysia. Furthermore, our research has found that these issues contain components that are promoted by religious pluralism and contradict the teachings of the Ahl alSunnah wa al-Jama'ah, which are held by the majority of Muslims in Malaysia. This argument is critical because any issue that occurs need to be reviewed and studied to see if it conflicts with the policy brought about by the concept of religious diversity. This research is also necessary to identify the policies brought about by religious diversity which aims to prevent it from spreading through an organisation or movement in Malaysia despite being cloaked in "exterior purity."
\end{abstract}

Keywords: Faith Issues in Malaysia; Religious Pluralism; Contemporary Issues in Islamic Thought; Ideological attacks; Exterior Purity

\footnotetext{
* Corresponding author: ahmadhebat.ah@gmail.com eISSN: 2636-9257 CPusat Dialog Peradaban Universiti Malaya, 2021 DOI: https://doi.org/10.22452/PERADABAN.vol14no1.1
} 


\begin{abstract}
Abstrak
Pada pasca modernisasi ini, terdapat pelbagai pemikiran baharu yang muncul dengan pelbagai ideologi yang dibawa seperti pluralisme agama. Pluralisme agama merupakan sebuah ideologi yang disebarkan di banyak negara termasuklah Malaysia. Pluralisme agama sangat berbahaya kerana ianya sebuah serangan ideologi yang menyerang pemikiran umat manusia dalam mengubah pegangan seseorang bahkan ianya membawa kepada kekeliruan terhadap kefahaman beragama dan memanipulasi sifat kepelbagaian beragama. Maka, perkara tersebut dianggap bakal menggugat pemikiran dan akidah sebenar seseorang khususnya buat penganut agama Islam. Terdapat pelbagai isu di Malaysia yang dikatakan bahawa ianya mempunyai kaitan dengan penyebaran fahaman pluralisme agama. Objektif kajian ini adalah untuk mengenalpasti isu-isu yang timbul yang dikaitkan dengan pluralisme agama di Malaysia. Objektif kedua, kajian ini juga akan membuat analisis awal terhadap permasalahan yang timbul melalui isu-isu pluralisme agama di Malaysia dengan mengaitkannya dengan dasar yang dibawa oleh pluralisme agama itu sendiri. Kajian ini akan menggunakan kaedah penyelidikan kualitatif dan lebih menfokuskan pengumpulan maklumat berdasarkan resensi kepustakaan. Artikel ini merumuskan dan mendapati bahawa banyak isu-isu yang timbul di Malaysia mempunyai kaitan dengan dasar yang dibawa oleh pluralisme agama. Tambahan pula, kajian ini telah membuat analisa awal bahawa isu-isu ini mempunyai unsur-unsur yang diperjuangkan oleh fahaman pluralisme agama dan ianya bercanggah dengan ajaran akidah Ahl al-Sunnah wa al-Jama'ah yang menjadi pegangan majoriti umat islam di Malaysia. Perbahasan ini amat penting supaya setiap isu yang timbul selepas ini perlulah diteliti dan dikaji sama ada ianya mempunyai perjuangan terhadap dasar yang dibawa oleh fahaman pluralisme agama. Selain itu, kajian ini penting untuk mengenalpasti dasar-dasar yang dibawa oleh pluralisme agama itu sendiri dan mengaitkannya terhadap sesebuah isu yang timbul demi untuk membanteras ia daripada terus disebarkan melalui sesebuah organisasi ataupun gerakan di Malaysia meskipun ianya berlindung di sebalik "kemurnian luaran".
\end{abstract}

Kata Kunci: Isu Akidah di Malaysia; Fahaman Pluralisme Agama; Isu-isu Semasa Pemikiran Islam; Serangan ideologi; Kemurnian Luaran

\title{
Pengenalan
}

Menurut Havis Aravik dan Choiriyah (2016), perkataan pluralisme agama itu sendiri boleh dipecahkan kepada 2 suku kata iaitu 'pluralisme' dan 'agama'. Pengkaji meletakkan bahawa ianya digabungkan dari 4 suku kata yang berbeza dan digabungkan menjadi sebuah istilah yang besar iaitu "plural", "isme". "a", dan "gama". Pluralisme agama juga dikenali sebagai "al-ta'addudiyyah al-diniyyah" dalam bahasa Arab, dan dalam bahasa Inggeris pula disebut sebagai "religious pluralism". Perkataan pluralisme agama ini bukanlah sebuah perkataan yang baru muncul tetapi ia merupakan sebuah perkataan yang timbul daripada permasalahan klasik yang mula mendapat tempat dalam masyarakat hari ini. Pengkaji tidak menafikan bahawa kajian-kajian mengenai pluralisme agama terutamanya dalam aspek perbahasan maknanya telah banyak 
dihujahkan dan dihuraikan oleh sarjana-sarjana Barat termasuklah sarjana-sarjana Muslim melalui karya dan penulisan-penulisan mereka seperti Haslina Ibrahim, Earnie Elmi Hilmi, Kamarudin Salleh, Gatot Suhirman, dan ramai lagi.

Menurut Onions (1952), pluralisme dipecahkan kepada 3 bahagian pengertian berdasarkan kamus Bahasa Inggeris iaitu (1) dalam "pengertian sosio-politik" iaitu sebuah sistem yang membenarkan aspek-aspek perbezaan yang wujud dalam mengakui kewujudan kepelbagaian dalam sesebuah kelompok, (2) dalam "pengertian filosofis" iaitu lebih menfokuskan kepada sistem pemikiran yang mempercayai wujudnya aliran pemikiran asas yang lebih daripada satu, dan (3) dalam "pengertian kegerejaan" kepada seseorang yang memegang lebih daripada satu atau dua jabatan secara serentak.

Dalam aspek bahasa, "pluralisme" merupakan gabungan daripada 2 suku kata iaitu "plural" dan "isme". "Plural" menurut Prof Dr. Faisal Ismail (2014) yang dikeluarkan daripada kamus The Random House Dictionary of the English Language adalah "pertaining or involving a plurality of persons or things" yang membawa maksud melibatkan sesuatu benda atau orang dengan kuantiti yang banyak. Menurut Abdul Moqsith Ghazali (2009), perkataan ini juga dikatakan merupakan asal daripada bahasa Latin iaitu plures yang bermaksud beberapa perkara yang berbeza. Makna kata 'isme' pulak tidak disebutkan secara langsung dalam Kamus Dewan bahasa dan Pustaka namun ianya disebutkan dalam Kamus Besar Bahasa Indonesia (KBBI) (2016) sebagai sebuah sistem kepercayaan dalam konteks sosial, politik, atau ekonomi. Dalam kamus bahasa Inggeris pula, 'ism' dikategorikan maknanya kepada 6 bahagian dan dalam kajian ini, pengkaji cenderung untuk melatari pemaknaannya kepada bahagian pertama iaitu a "particular principle or the beliefs and ideas of a particular person is where a political belief or religion based on" yang membawa maksud sesuatu fahaman politik atau agama adalah berdasarkan prinsip-prinsip dan kepercayaan seseorang individu.

Perkataan "agama" pula berasal dari bahasa Sanskrit yang merupakan gabungan 2 suku kata iaitu 'a' yang bermaksud 'tidak', dan 'gama' pula bermaksud 'kacau' (Paul Procter, 1978). Apabila digabungkan, ianya membawa maksud 'tidak kacau' ataupun boleh juga membawa maksud sebagai 'kebenaran mutlak' (Havis Aravik, 2016). Menurut Ezi Fadilla dan Azhari Andi (2016), dalam bahasa Arab pula ia disebut sebagai al-din yang dieertikan sebagai aturan atau sistem yang merangka kehidupan dan dijadikannya sebagai sebuah kepercayaan dan disebut juga sebagai religion dalam bahasa Inggeris. Namun begitu, pendefinisian istilah 'agama' ini amat banyak diperdebatkan dalam kalangan ahli sarjana dalam mencapai persetujuan dalam polemik pemikiran sehingga ianya sukar dipersetujui sebulat suara oleh majoriti ahli intelektual dan sukar disepakati antara satu sama lain. Dalam hal ini, Abdul Moqsith Ghazali (2009) mengambil jalan tengah dengan melihat kepada 3 pendekatan dalam mendefinisikan istilah agama ini dari sudut pengamatannya iaitu dari segi fungsi, institusi dan substansi. 
Dalam aspek istilah pula, terdapat pelbagai perbahasan oleh ahli-ahli intelektual mengenai pengertian pengistilahan ini apabila ianya disandingkan di antara satu sama lain dengan membentuk sebagai sebuah istilah iaitu "pluralisme agama". Menurut Hashim Kamali (2011) dalam penulisannya menerusi paparan awal di The New Straits Times (Kuala Lumpur) menghuraikan kepada 3 ayat dalam al-Quran dalam menjelaskan makna pluralisme agama sebagai "The said three verses undoubtedly entitled the Muslims to say that Islam is a true religion, but they stop short of denying others to hold the same about their religions" yang bermaksud seseorang yang beragama Islam itu mengakui bahawa Islam adalah agama yang benar, namun mereka tidak menafikan bahawa agama lain turut memiliki persamaan yang sama.

Menurut Nurcholish Madjid pula, pluralisme agama merupakan sebuah ikatan antara manusia dalam memupuk keselamatan dan keharmonian disamping menyingkirkan kefanatikan seseorang terhadap agamanya sendiri. Beliau menegemukakan hujah bahawa bumi ini akan hancur sekiranya Allah tidak mengimbangi bumi ini dengan golongan yang berbeza untuk saling mengawasi sesama manusia dalam memelihara kekuatan bumi (Havis Aravik dan Choiriyah, 2016; Budhy Munawar Rahman, 2004). Pendefinisian ini juga turut dijelaskan oleh Mohd Fauzi Hamat dan Wan Adli Wan Ramli (2007) bahawa pluralisme agama adalah suatu keadaan yang melahirkan sikap toleransi kepada pihak lain dan melahirkan sebuah pemikiran yang mendokong kepada perkongsian kebenaran yang diklasifiksikannya kepada pemilikan bersama. Dalam hal ini, ia menunjukkan bahawa pluralisme agama menyusup masuk dalam kewujudan kemajmukan agama sebagai sebuah solusi dalam melahirkan masyarakat yang harmoni dalam kepelbagaian kaum dan juga agama. Namun, pernyataan yang mengatakan bahawa pluralisme agama merupakan satu-satunya solusi yang boleh mewujudkan keharmonian atau toleransi dalam kepelbagaian beragama adalah tidak konsisten dengan apa yang diperjuangkan oleh fahaman pluralisme agama itu sendiri. Ini adalah kerana pluralisme agama mengakui bahawa semua agama adalah sama dan benar serta menuju kepada Tuhan yang sama. Hal yang sama telah dikritik oleh Wan Adli Wan Ramli (2012) dan beliau menolak kesemua pendefinisian pluralisme agama yang menunjukkan kecenderungan kepada toleransi agama.

Selain itu, Majlis Ulama Indonesia (2005) juga menghuraikan pluralisme agama sebagai "sebuah fahaman yang berpegang kepada semua agama adalah sama dan disebabkan itu setiap penganut agama tidak boleh mewartakan bahawa agamanya sahaja yang benar sedangkan agama yang lain adalah sesat. Bukan itu sahaja, pluralisme agama juga berpegang bahawa setiap penganut agama akan hidup bersamasama di syurga kelak". Hujah dan keputusan pemaknaan ini adalah diambil berdasarkan keputusan majoriti melalui musyawarah di kalangan ulama-ulama di Indonesia. Menurut Prof. Dr. Hamka (2012), pemaknaan ini dikuatkan lagi berdasarkan Persidangan Parlimen antara agama-agama di Chicago pada tahun 1893 yang menghuraikan pluralisme agama adalah sebuah gagasan yang berpegang kepada bukan hanya sebuah agama sahaja yang benar dan tidak boleh ada "truth claim" dalam diri seseorang penganut dengan hujah bahawa seseorang penganut itu tidak boleh 
menyatakan bahawa jalannya sahaja yang benar secara mutlak dalam arah menuju kepada Tuhan.

Dalam hal ini, pengkaji cenderung dengan pemaknaan pluralisme agama yang dibawa oleh Mohd Fauzi Hamat dan Wan Adli Wan Ramli. Pengkaji cenderung dengan menyatakan bahawa pluralisme agama adalah daripada pengertian filosofis iaitu sebuah sistem pemikiran dan kepercayaan terhadap perkongsian kebenaran kepada setiap agama dalam menzahirkan toleransi antara agama yang dilatari dengan "kemurnian luaran" sehingga ber-i'tiqad bahawa semua agama adalah sama benar.

Pendefinisian tersebut sedikit sebanyak menerangkan mengenai pembawakan dan fahaman yang dibawa oleh pluralisme agama. Dalam pengkajian ini, pengkaji akan menggunakan kaedah penyelidikan kualitatif dan lebih menfokuskan pengumpulan maklumat berdasarkan resensi kepustakaan. Hal ini bertujuan untuk mengkaji dan menghuraikan sesuatu isu yang sedang berlaku di samping memudahkan pengkaji dan juga pembaca. Oleh itu, kajian ini amat penting dalam mengenalpasti isu-isu yang timbul yang dikaitkan dengan pluralisme agama di Malaysia dan pengkaji juga akan mengkaji kaitan isu-isu tersebut dengan dasar yang diperjuangkan oleh pluralisme agama.

\section{Dapatan dan Perbincangan Kajian}

Menurut Abdullah Muhammad Zin (2018), pluralisme agama merupakan sebuah fahaman yang ditegah penyebarannya di Malaysia disebabkan oleh ajarannya yang bercanggah dengan akidah Ahl al-Sunnah wa al-Jama'ah. Hasniza Hussain (2020) menyatakan bahawa terdapat pelbagai isu yang timbul dan dikaitkan dengan pembawakan dan penyebaran pluralisme agama di Malaysia yang hangat dibincangkan dan menjadi buah mulut dalam setiap lapisan sama ada masyarakat biasa mahupun para cendekiawan. Hujah-hujah terhadap isu-isu yang dikupas akan membuktikan wajah pluralisme agama sama ada ianya membahayakan akidah umat Islam ataupun tidak terutama yang berpegang kepada akidah Ahl al-Sunnah wa al-Jama'ah. Terdapat pelbagai isu yang dikatakan dan dikaitkan dengan pembawakan fahaman pluralisme agama ini.

\section{Kebebasan beragama}

Isu pertama yang timbul adalah isu kebebasan beragama yang merupakan isu paling banyak diperjuangkan oleh golongan yang berfahaman pluralisme. Bahkan menurut pengkaji, kebebasan agama ini bukanlah sekadar isu tetapi ia merupakan sebuah dasar yang menjadi tunjang kepada fahaman pluralisme agama ini. Hal ini demikian kerana ia merupakan salah satu gagasan yang diperjuangkan oleh pluralisme agama dalam membentuk sebuah falsafah yang mengikut kepada teori dan fahaman mereka. Menurut pengkaji, berkemungkinan bahawa wujud pihak yang cuba menghuraikan "kebebasan beragama" yang termaktub dalam perlembagaan negara sebagai sebuah kebebasan yang mutlak. Contohnya, timbul sebuah isu apabila mereka mempertikaikan dan mengkritik terhadap serbuan yang dilakukan oleh pihak berkuasa keatas mereka yang 
cuba menyebarkan ajaran selain daripada Islam kepada umat Islam berdasarkan laporan dan kajian dari Muhammad Fathi bin Yusof, Mohd Al-Ikhsan Ghazali, dan Nik Mohd Zaim Nik Abdul Rahim (2014).

Dalam kritikan ini, hujah yang dikemukakan adalah berdasarkan perkara 11 Perlembagaan Persekutuan yang membenarkan hak kebebasan beragama di Malaysia. Menurut penelitian pengkaji, pertikaian ini dilihat sebagai selumbar pluralisme agama yang cuba menyamaratakan kesemua agama dalam aspek penyebarannya yang terbuka. 'Kebebasan' yang digariskan cuba dimanipulasikan oleh pihak tertentu untuk mengaburi mata masyarakat awam sebagai salah satu keadilan yang mesti dinikmati oleh kesemua agama atas dasar kebebasan beragama. Menurut akta 1260/2006 dalam perlembagaan persekutuan, 'kebebasan' yang termaktub sebagai salah satu garis panduan perlembagaan adalah kebebasan dari aspek pengamalan agama masingmasing dan pengajarannya terhadap penganutnya sendiri. Dalam hal ini, menurut akta yang sama, Islam tetap menjadi keutamaan bahawa agama Islam adalah agama rasmi bagi kerajaan Malaysia mengikut perkara 3(1) Perlembagaan Persekutuan.

Menurut Earnie Elmie Hilmi, Kamarudin Salleh, dan Nur Farhana Abdul Rahman (2019), antara tokoh yang agak lantang dalam mempromosikan fahaman pluralisme agama ini adalah Chandra Muzaffar yang mempertikaikan fatwa yang dikeluarkan oleh Majlis Agama Islam Selangor (MAIS) yang dikatakan bercanggah dengan konsep kebebasan yang termaktub dalam Rukun Negara. Hal ini kerana, Chandra Muzaffar (2014) menganggap bahawa keseluruhan konsep yang dibawa oleh Rukun Negara itu sendiri adalah berpaksikan kepada "kebebasan" dan "hak untuk memilih". Menurut Earnie Elmie Hilmi, Kamarudin Salleh, dan Nur Farhana Abdul Rahman (2019) juga, Chandra Muzaffar pernah memuatkan penulisan karyanya (artikel) yang mendokong fahaman PA dalam akhbar The Star iaitu 'What pluralism means to Islam' dan 'Understanding liberalism and religious pluralism'.

Selain itu juga, Zainah Anwar turut mendokong fahaman dan gagasan yang dibawa oleh pluralisme agama dalam penulisannya di sebuah artikel New Straits Times yang bertajuk "Mediation the wiser path to take". Dalam perbincangan itu, beliau menyentuh mengenai perkara ataupun proses pertukaran agama khususnya mereka yang dari agama Islam yang hendak bertukar ke agama yang lain. Beliau menyatakan bahawa pegangan iman seseorang bukanlah bawah bidang kuasa sesebuah kerajaan dan ianya hanyalah pegangan dan hak seseorang individu. Hal ini kerana, beliau berpendapat bahawa hak kemanusiaan yang perlu ada pada setiap orang adalah dengan berkelakuan baik. Zainah Anwar (2007) mempertikai dan menyatakan bahawa tidak adil bagi seseorang yang beragama Islam yang ingin keluar daripada agama tersebut dihalang kerana ianya bercanggah dengan hak kebebasan seseorang.

Seterusnya, Hashim Kamali turut mengarang sebuah artikel yang bertajuk "Islam's religious pluralism in context" yang mendokong fahaman dan idea yang dibawa oleh pluralisme agama. Dalam konteks ini, kefahaman kebebasan ini boleh dibahagikan 
kepada 2 bahagian iaitu "kebebasan mutlak" dan "kebebasan berpanduan". Tidak dinafikan bahawa Islam adalah sebuah agama yang tidak memaksa berdasarkan dalil al-Quran yang bermaksud:

"Tidak ada paksaan untuk (memasuki) agama (Islam); sesungguhnya telah jelas jalan yang benar daripada jalan yang sesat. Kerana itu barang siapa yang ingkar kepada Thaghut dan beriman kepada Allah, maka sesungguhnya ia telah berpegang kepada buhul tali yang amat kuat yang tidak akan putus. Dan Allah Maha Mendenengar Lagi Maha Mengetahui." (Al-Baqarah, 256).

Namun begitu, ia bukanlah menjadi sebuah tiket untuk seseorang yaang beragama Islam bertindak bebas dalam amalan dan iqtikadnya. Menurut tafsir Imam Ibn Kathir, ketidakpaksaan ini adalah tertumpu kepada mereka yang bukan Islam untuk memeluk Islam tanpa ada sebarang paksaan ataupun desakan dari pihak yang lain. Hujah ini dijelaskan berdasarkan ayat 'qad tabayyana al-rushd min al-ghayy' iaitu apabila Islam itu telah dijelaskan dan dibuktikan terhadap kebenarannya, maka tidak perlu lagi sebarang unsur paksaan terhadap mereka yang bukan Muslim untuk bersyahadah. Muzakarah Fatwa di Malaysia turut membincangkan mengenai kekeliruan pluralisme agama dalam konteks akidah Islam yang menyeru kepada kesamarataan agama. Muzakarah Jawatankuasa Fatwa Majlis Kebangsaan Hal Ehwal Ugama Islam Malaysia kali ke 74 pada 25 - 27 Julai 2006 telah menggariskan dan menetapkan bahawa pluralisme agama adalah sebuah fahaman yang sesat untuk diamalkan.

Berdasarkan isu-isu yang timbul ini, pengkaji menyimpulkan bahawa setiap isu ini didasari dengan dasar perjuangan pluralisme agama iaitu kebebasan beragama. Penimbulan isu-isu ini mestilah dipandang serius dan ditentang sepenuhnya kerana ia akan melibatkan perubahan dasar kerajaan dalam aspek keagamaan sekiranya pertikaian dan desakan mereka didengari dan diangkat sebagai sebuah solusi dalam "keharmonian" dalam kehidupan masyarakat yang pelbagai yang boleh diklasifikasikan oleh pengkaji sebagai "kemurnian luaran". Isu-isu seperti ini amat berbahaya khususnya kepada masyarakat awam kerana isu ini memancing dengan umpan "keharmonian" dan "kebebasan" yang secara asasnya adalah amat baik dan murni.

Kebebasan di dalam Islam adalah "kebebasan berpanduan" kerana Islam amat mementingkan i'tiqad di dalam hati pada setiap masa bahawa hanyalah agama Islam yang paling benar dan mendapat redha di sisi Allah s.w.t. Akan tetapi, menurut penelitian pengkaji, kebebasan yang dibawa oleh PA adalah sebuah "kebebasan mutlak" yang tidak ada sebarang halangan ataupun batas dari setiap aspek termasuklah aspek pegangan di dalam hati. Hal ini berdasarkan idea yang dibawa oleh John Hick (2005) mengenai pluralisme agama iaitu "the belief that no one religion has a monopoly of the truth or of the life that leads to salvation" yang bermaksud bahawa tidak ada satu agama pun yang boleh mengatakan bahawa hanya agamanya sahaja yang betul dan 
membimbing kearah keselamatan yang sebenar Gagasan ini jelas sekali berbeza dengan panduan yang telah ditetapkan di dalam Islam bahkan ianya bercanggah dengan garis panduan undang-undang Malaysia yang mengisytiharkan Islam adalah sebuah agama rasmi di Malaysia.

\section{Penggunaan kalimah Allah}

Isu kedua yang tercetus adalah isu membenarkan penggunaan kalimah 'Allah' kepada mereka yang bukan Islam di Malaysia. Isu ini kembali hangat pada tahun ini (2021) dikala dunia sedang menghadapi salah satu wabak terbesar iaitu COVID-19 apabila perlunya kembali sebuah perbincangan diantara mufti-mufti di seluruh Malaysia untuk membincangkan mengenai status penggunaan kalimah 'Allah' oleh bukan Islam. Hal ini tidak lain dan tidak bukan kerana adanya desakan dari pihak Kristian yang menyuarakan dan mempertikaikan hak penggunaan kalimah tersebut terhadap mereka. Pada 10 Mac 2021, menurut Willie Jude dan Goh Pei Pei (2021), Mahkamah Tinggi telah memutuskan bahawa larangan terhadap penggunaan nama 'Allah', 'Baitullah', 'solat', dan 'kaabah' oleh mereka yang bukan Islam oleh Kementerian Dalam Negeri pada tahun 1986 adalah tidak berpelembagaan dan tidak sah disisi undang-undang.

Berikutan kenyataan ini, pelbagai agensi kerajaan dan juga bukan kerajaan telah bertindak dan bersuara agar keputusan ini dibincangkan semula oleh Mahkamah Tinggi. Namun begitu, menurut Willie Jude dan Goh Pei Pei (2021) juga, sekumpulan Ahli Parlimen dan ADUN dari Sabah dan Sarawak memberikan kenyataan sebulat suara agar kerajaan menerima keputusan yang telah dikeluarkan oleh Mahkamah tinggi dan tidak melakukan apa-apa tindakbalas terhadap ketidakpuashatian. Menurut Luqman Arif Abdul Karim (2021) pula, Datuk Seri Dr Zulkifli Mohamad Al-Bakri, Menteri di Jabatan Perdana Menteri (Hal Ehwal Agama) menyokong tindakan Kementerian Dalam Negeri (KDN) dan kerajaan yang mengfailkan proses rayuan pada 15 Mac 2021 terhadap keputusan yang dikeluarkan oleh Mahkamah Tinggi dan beliau juga telah membuat perbincangan khas dan mengemukakan hasil perbincangan di Majlis Raja-Raja pada 17 Mac 2021.

Mahkamah Tinggi telah memutuskan bahawa penggunaan kalimah 'Allah', 'Baitullah', 'solat', dan 'kaabah' dibenarkan kepada penganut Kristian dalam penerbitan-penerbitan bagi tujuan pendidikan mereka adalah berdasarkan huraian penghakiman setebal 96 muka surat oleh Hakim Datuk Nor Bee Ariffin. Kebenaran ini adalah bersyarat iaitu setiap penggunaannya di dalam setiap penerbitan mestilah menyatakan di hadapan atau di kulit buku tersebut dengan jelas perkataan "untuk agama Kristian. Menurut Hakim Datuk Nor Bee Ariffin, kebenaran penggunaan kalimah-kalimah ini pada Mei 1986 adalah berdasarkan polisi kerajaan dan ianya termaktub kepada penerbitan agama bagi tujuan pendidikan sahaja. Manakala, sebab dilarang penggunaannya pula adalah untuk memelihari keselamatam daripada berlakunya sebarang salah faham antara penganut Islam dan Kristian (Bernama, 2021). 
Pengkaji tidak menafikan bahawa telah banyak kupasan yang dilakukan terhadap isu ini, namun pengkaji melihat bahawa keterbukaan dalam kebenaran penggunaan kalimah ini oleh mereka yang bukan Islam berdasarkan statistik dalam masyarakat majmuk di Malaysia yang majoritinya beragama Islam hanya akan mendatangkan kesalahan bahasa dalam Bible itu sendiri dan akan mewujudkan ketidak selarian dan kekeliruan terhadap penganut Kristian yang membaca Bible itu sendiri. Di samping itu juga, ianya sekaligus akan membuka kepada ruang-ruang permusuhan antara agama yang boleh mencetuskan pergaduhan dan provokasi yang tidak diingini. Justeru, pengkaji melihat bahawa kebenaran penggunaan kalimah ini akan membuka kepada liang-liang penyebaran pemikiran seperti pluralisme agama yang menggagaskan kepada teori bahawa semua agama adalah sama benar dan menuju kepada Tuhan yang sama berdasarkan kajian Wan Adli Wan Ramli (2012). Kebenaran penggunaan istilah ini juga boleh mengelirukan pembaca terutamanya kepada umat Islam di Malaysia sehingga boleh mencetuskan kegoyahan pegangan akidah seseorang.

Pengkaitan ini disokong dan disebut dalam sebuah artikel oleh Shawaliah Hadir (2021) yang menyatakan bahawa penggunaan kalimah 'Allah' dalam penerbitan pendidikan ini hanya akan membuka kepada ruang kemurtadan dan juga campur tangan pemikiran PA dan Islam. Dalam isu ini, menurut laporan Ahmad Sanusi Azmi (2021), Prof Syed Naquib al-Attas menyatakan bahawa permohonan penggunaan kalimah 'Allah' dari pihak Kristian di Malaysia untuk berdoa dalam Bahasa Malaysia dan ingin bersikap patriotik hanyalah sebuah perkara yang tidak masuk akal kerana istilah 'Allah' itu sendiri bukanlah merupakan istilah Bahasa Malaysia dan konsep ketuhanan antara Islam dan Kristian amatlah berbeza.

Selain itu, berdasarkan Shawaliah Hadir (2021) juga, Aminuddin Yahaya iaitu pengerusi Pertubuhan-pertubuhan Pembela Islam (Pembela) yang mewakili badan bukan kerajaan (NGO) menyatakan bahawa keputusan ini akan membuka kepada ruang penghinaan terhadap kalimah suci ini dan ianya juga akan mengelirukan masyarakat umum di Malaysia. Beliau juga memohon kepada Raja-Raja Melayu yang merupakan ketua kepada agama Islam di negeri masing-masing untuk mengekang dan membanteras penggunaan kalimah suci ini agar tidak disalahguna oleh mereka yang tidak sepatutnya.

Menurut Ruwaida Md Zain (2021), kebenaran ini juga mendapat reaksi daripada Sultan Selangor, Sultan Sharafuddin Idris Shah Al-Haj yang melarang serta mencegah sebarang penggunaan kalimah 'Allah' di negeri tersebut dalam terjemahan Kitab Bible, percetakan, serta segala bentuk penulisan dalam agama Kristian. Namun begitu, baginda tidak menghalang sebarang penggunaan perkataan 'Tuhan' dalam penerjemahan 'God'. Baginda juga bertitah:

"Apa gunanya beta menjadi Ketua Agama Islam Selangor jika beta gagal untuk menjamin kemuliaan kalimah Allah dan kesucian Islam dari dicemari oleh pihak yang mempunyai agenda tersendiri..." "Beta sentiasa menekankan supaya rakyat beta dapat menghormati 
kepercayaan agama masing-masing dan tidak cuba untuk menyentuh sensitiviti agama masing-masing yang boleh merosakkan perpaduan kaum di Selangor ini..." "Jika umat Islam boleh menghormati penganut agama lain dengan tidak mencampuri urusan berkaitan agama mereka maka beta juga menggesa penganut agama untuk menghormati penganut agama Islam khususnya dalam penggunaan kalimah Allah yang menjadi pegangan utama umat Islam.” (Berita Harian, 2021).

\section{Penubuhan Suruhanjaya Antara Agama (Inter Faith Commission atau IFC)}

Isu ketiga adalah berkenaan perancangan penubuhan Suruhanjaya Antara Agama (Inter Faith Commission-IFC). Perancangan penubuhan ini bermula apabila Majlis Perundingan Malaysia Agama Buddha, Kristian, Hindu dan Sikh menghantar memorandum mereka kepada Majlis Peguam pada 21 Ogos 2001. Berikutan penubuhan ini, ianya mendapat tentangan hebat oleh masyarakat Islam sehingga tertubuhnya Allied Coordinating Committee of Islamic NGOs (ACCIN) ${ }^{1}$ sekaligus melancarkan bantahan secara keras terhadap IFC. Menurut Mohd Roslan (2013) dalam penulisaanya dalam sebuah artikel, tuntutan IFC ini telah mendapat tentangan habishabisan oleh NGO Islam dan ditolak cadangan penubuhannya oleh kerajaan.

Berdasarkan Earnie Elmie Hilmi, Kamarudin Salleh, Nur Farhana Abdul Rahman (2019), antara tuntutan yang menjadi perjuangan IFC adalah penuntutan hak asasi manusia adalah dalam aspek keagamaan. Tuntutan yang dibawa oleh IFC adalah menyerupai Suruhanjaya Hak Asasi Manusia Malaysia (SUHAKAM) yang menjadi wakil atau badan yang mendengar keluhan dan suara masyarakat awam dalam aspek keagamaan. Pembawakan atau tuntutan IFC ini mendapat tentangan terutamanya daripada badan-badan yang didasari oleh agama Islam dan secara jelas telah termaktub di negara Malaysia bahawa Islam adalah agama rasmi di negara ini. Malik Imtiyaz Sarwar (2005) menyatakan bahawa berdasarkan Jawatankuasa Penyelaras Bersekutu NGO Islam (ACCIN), agensi ini mengeluarkan kenyataan bahawa penubuhan IFC ini perlu diteliti kerana mereka melihat wujudnya agenda tersembunyi yang dirancang oleh pihak dalaman.

Menurut Earnie Elmie Hilmi, Kamarudin Salleh, Nur Farhana Abdul Rahman (2019) juga, ACCIN menyatakan bahawa penubuhan IFC ini didakwa mempunyai halatuju yang tersendiri untuk meminda undang-undang yang sudah termaktub mengenai perkara berkaitan agama Islam atas dasar memperjuangkan hak asasi manusia. IFC juga ingin menggagaskan hak kesamarataan dalam agama sehingga seseorang itu bebas untuk memilih agama yang ingin dianutinya dan seseorang Muslim tidak akan terhalang sekiranya ingin menukar asal agama mereka. Hak sama rata ini jelas sekali

\footnotetext{
${ }^{1}$ Allied Coordinating Committee of Islamic NGOs (ACCIN) atau Gabungan Pertubuhan Islam Bukan Kerajaan merupakan badan induk kepada NGO-NGO Islam di Malaysia. Ahli ACCIN antaranya ialah PERKIM, PUM, MUAFAKAT, ABIM, ISMA dan lain-lain. https:// accinmalaysia.wordpress.com/about. (3 Februari 2018).
} 
mempunyai persamaan seperti gagasan dan dasar yang diperjuangkan oleh pluralisme agama dalam perjuangan mereka.

Oleh itu, menurut penelitian pengkaji berdasarkan kenyataan tersebut, IFC dan juga pluralisme agama pastinya mempunyai kaitan atas dasar sifat yang diperjuangkan oleh pluralisme agama itu turut didasari oleh perjuangan IFC. Dalam pada masa yang sama, hal ini akan membuka ruang kepada mereka yang bukan Islam untuk mencampuri hal ehwal agama Islam dalam setiap sudut berdasarkan kehendak dan pemikiran mereka. Penuntutan hak asasi manusia bukanlah permasalahannya kerana sedia maklum bahawa setiap manusia mempunyai hak dan ruang dalam kehidupan mereka. Namun, hak ini menjadi permasalahan apabila ia menyentuh aspek keagamaan. Pengkaji menilai bahawa isu ini diketengahkan oleh mereka yang berfahaman pluralisme agama dalam memperjuangkan dasar kebebasan agama tetapi berlindung disebalik hak asasi manusia yang secara asasnya pasti disokong oleh segenap masyarakat. Menurut pengkaji, penubuhan IFC ini amat baik untuk diteruskan tetapi bukanlah dalam aspek keagamaan khususnya di Malaysia. Pengkaji tetap memilih bahawa aspek keagamaan perlu diselia dibawah mereka yang berautoriti agar ianya tidak diselewengkan dan dilonggarkan di samping menjaga keharmonia ke semua agama di Malaysia.

International Covenant Isu keempat pula adalah isu dalam menandatangani sebuah perjanjian antarabangsa iaitu perjanjian International Covenant on the Elimination of All Forms of Racial Discrimination (ICERD). Menurut Kartini Aboo Talib @ Khalid dan Suraiya Ishak (2019), ICERD merupakan salah satu undang-undang yang digariskan di bawah Pertubuhan Bangsa-Bangsa Bersatu (PBB) dan ianya bertujuan untuk menghapuskan segala bentuk penindasan dan diskriminasi dari sudut ekonomi, sosial, dan hak asasi manusia. Dari aspek luaran, perjanjian ini boleh dikategorikan sebagai sebuah perjanjian 'murni' dan 'adil' kerana ia memperjuangkan hak-hak individu sekaligus dapat meningkatkan keharmonian yang didahagakan oleh setiap negara yang mempunyai masyarakat yang berlainan agama dan latar belakang.

Kamaruzaman Mohamad (2019) menyatakan bahawa idea ratifikasi ICERD ini telah menarik tumpuan awam untuk mencegah dan memberontak dalam menggagalkan perjanjian ini untuk ditandatangani. 8 Disember 2018 menjadi mata terhadap penolakan rakyat terhadap perjanjian tersebut dengan menyertai himpunan gergasi di Dataran Merdeka untuk membawa suara ketidakpuas hatian untuk meneruskan perjanjian tersebut. Kartini Aboo Talib @ Khalid dan Suraiya Ishak (2019) turut menzahirkan sebab penolakan ICERD ini adalah kerana mereka mempercayai bahawa hasil perjanjian ini mengakibatkan penolakan kuasa Raja-raja, menggugat keistimewaan kedudukan orang melayu, dan mengancam kedudukan agama Islam sebagai agama Persekutuan.

Mufti Wilayah Persekutuan pada ketika itu, Datuk Seri Dr Zulkifli Mohamad Al Bakri turut menolak ratifikasi ICERD ini dengan alasan bahawa ianya akan membawa keburukan yang lebih besar daripada kebaikan dan tidak sesuai diamalkan di negara 
Malaysia. Beliau juga berpendapat bahawa hasil perjanjian ini akan membuatkan ianya lebih berkuasa daripada Majlis Raja-raja yang maklum bidang kuasanya dalam menjaga kesucian agama-agama bagi setiap negeri. Tambahan pula menurut beliau, justifikasi perjanjian ini hanyalah akan membuka pintu untuk mana-mana pihak dalam menyerang dan campur tangan terhadap kedudukan agama Islam di Malaysia (Sinar Harian, 2018).

Penolakan disebabkan oleh pembawakannya dalam menyamakan kedudukan agamaagama di Malaysia perlu ditentang sepenuhnya kerana ianya akan menjadi modus operandi bagi pembawakan fahaman pluralisme agama. Tidak dinafikan bahawa adanya kebaikan perjanjian ICERD ini terutamanya kepada golongan minoriti dalam menuntut hak-hak mereka sekiranya tertindas ataupun tidak dipandang. Namun begitu, ianya tidaklah begitu sesuai diamalkan di negara Malaysia kerana undang-undang di Malaysia sendiri telah menyatakan secara jelas bahawa Islam adalah agama rasmi dan agama-agama yang lain boleh diamalkan di negara Malaysia tanpa ada sebarang halangan atau tentangan. Undang-undang yang sedia ada ini sekaligus membuktikan bahwa Malaysia tidaklah menindas golongan-golongan minoriti malah memberikan kebebasan untuk setiap rakyatnya. Menurut pengkaji, usaha dalam mencapai perjanjian ini di Malaysia hanyalah alat bagi mereka yang berfahaman pluralisme agama untuk menyebarkan fahaman mereka bagi mengaburi mata masyarakat dengan berselindung disebalik perjuangan hak asasi manusia.

Berkenaan isu ini juga, pengkaji meneliti bahawa mereka yang berfahaman pluralisme agama sekali lagi mengetengahkan isu kemanusiaan sama seperti isu yang dibincangkan sebelum ini disamping untuk membawa dasar mereka yang tersendiri dalam menyentuh hal-hal keagamaan. Pengkaji melihat bahawa mereka bersuara dalam isu ini untuk menolak segala diskriminasi ke atas masyarakat dalam hal ekonomi, sosial, dan sebagainya tetapi tidak menyebut bahawa hasil perjanjian ini juga akan menyentuh aspek keagamaan. Dalam hal ini, pengkaji menganggap bahawa mereka yang berfahaman pluralisme agama jelas sekali bercanggah dengan ajaran Islam yang sebenar kerana mereka "kecut perut" untuk membentangkan perkara yang sebenar terhadap hasil perjanjian ini demi meraih kepercayaan masyarakat dengan bersembunyi disebalik "kemurnian luaran". Isu ini amat penting untuk dibahaskan kerana isu ini bukanlah ditimbulkan dalam kelompok kecil, tetapi ia melibatkan dasar dan pembentukan negara.

\section{Nilai kesamarataan agama}

Isu kelima yang dibincangkan pula adalah berkenaan sebuah laman sesawang yang dikenali sebagai "Projek Dialog". Laman sesawang2 ini menyediakan sebuah platform terutamanya kepada "suara terpinggir" untuk mengeluarkan atau menerbitkan artikel dan penulisan berkaitan bangsa dan agama. Laman sesawang ini menfokuskan perbincangan berkenaan isu-isu terkini dan meletakkan platform ini sebagai sebuah

\footnotetext{
${ }^{2}$ https://projekdialog.com/
} 
perbincangan dalam memupuk toleransi antara agama. "Projek Dialog" ini juga mempunyai tujuannya yang tersendiri dalam memupuk seni perdebatan dan persefahaman antara agama, kaum, ideologi, dan cara hidup khususnya di Malaysia.

Secara luarannya, pengkaji melihat laman sesawang ini amat baik dan penting untuk meningkatkan keharmonian di negara ini. Namun begitu, antara penulisan yang diterbitkan oleh Tan (2013) melalui ruang wacana ini ada menyatakan dengan jelas bahawa kedamaian hidup bersama adalah "meletakkan nilai kesamarataan, keharmonian dan keamanan antara agama". Menurut penulis, nilai kesamarataan ini adalah dalam semua aspek dan pengkaji beranggapan bahawa penulis memasukkan sekali aspek keagamaan dalam nilai tersebut. Menurut Anis Malik Thoha (2011), nilai kesamarataan dalam beragama merupakan salah satu gagasan dan dasar yang dipegang oleh mereka yang berfahaman pluralisme. Kesamarataan di sini amat berbahaya kerana ianya akan menghakis pegangan penganut agama seseorang disamping membenarkan di dalam hati kebenaran agama yang lain. Perkara ini amat penting untuk dinilai kerana laman sesawang ini masih aktif digiatkan atas dasar 'toleransi' dan nama 'dialog'. Oleh itu, dalam hal ini, pengkaji menilai bahawa pemilik laman sesawang ini berkemungkinan salah faham terhadap makna dan gagasan dialog yang sebenar kerana toleransi yang sebenar jelas sekali berbeza dengan toleransi yang ingin dibawa oleh mereka yang berfahaman pluralisme.

Menurut Haslina Ibrahim (2011), falsafah pluralisme agama adalah setiap agama mepunyai huraian dan definisi yang berbeza mengenai Tuhan masing-masing sehingga timbulnya persoalan bahawa dakwaan dan perincian siapa yang benar dan paling tepat. Dalam hal ini, pluralisme agama hadir sebagai penghubung kepada keharmonian semua agama dengan mengiktiraf dakwaan setiap agama mengenai Tuhan mereka dengan menyatakan bahawa kebenaran huraian Tuhan itu tidak mutlak kepada sebuah agama sahaja.

Fahaman dan gagasan yang dibawa pluralisme agama ini jelas sekali berbahaya kepada masyarakat dalam aspek pemikiran dan juga pegangan (akidah) seseorang. Hal ini boleh dilihat dan dinilai berdasarkan isu-isu yang hadir dalam menyerang pemikiran manusia pada setiap lapisan masyarakat supaya bentuk pemikiran mereka diterima dan diamalkan. Perbahasan isu-isu ini amat penting dibahaskan untuk melihat kaitannya dengan dasar yang dibawa oleh pluralisme agama. Fahaman pluralisme agama ini menyebarkan pegangan mereka dengan berselindung disebalik kemanisan "hak asasi manusia". Pembawakan dan penyerangan pluralisme agama ini tidaklah menggunakan kekerasan atau desakan fizikal, namun ianya datang sebagai jarum halus dalam meniti dan menusuk kepada pemikiran seseorang sehingga boleh menyebabkan keraguan dan kekacauan akidah.

\section{Kesimpulan}

Fahaman pluralisme agama jelas sekali menunjukkan bahawa ianya bercanggah dengan ajaran Islam yang sebenar. Hal ini telah dibuktikan melalui pelbagai kajian 
yang telah dilakukan sebelum ini. Kemunculan isu-isu ini yang dikaitkan dengan pluralisme agama menunjukkan bahawa fahaman ini telahpun memasuki ke dalam kancah penyebarannya di Malaysia. Kajian ini juga dikuatkan lagi melalui bukti-bukti terkini yang menunjukkan bahawa fahaman pluralisme agama adalah bercanggah dengan ajaran akidah Ahl al-Sunnah wa al-Jama'ah yang menjadi pegangan majoriti umat islam di Malaysia. Kajian ini telah membuat analisa awal bahawa isu-isu ini mempunyai unsur-unsur yang diperjuangkan oleh fahaman pluralisme agama dan jelas sekali bercanggah dengan prinsip Islam yang sebenar. Kemasukan fahaman ini ke dalam organisasi dan perjuangan di Malaysia amatlah berbahaya kepada agama Islam khususnya, masyarakat, dan juga negara yang berprinsipkan Islam sebagai agama rasmi. Setiap isu yang timbul ini jelas sekali mempunyai ciri-ciri terhadap dasar dan pegangan fahaman pluralisme agama yang boleh memesongkan pemikiran masyarakat dengan menganggap bahawa perkara tersebut amat penting khususnya buat negara Malaysia yang mempunyai masyarakat yang berbilang kaum. Perbahasan ini amat penting supaya setiap isu yang timbul selepas ini perlulah diteliti dan dikaji sama ada ianya mempunyai perjuangan terhadap dasar yang dibawa oleh fahaman pluralisme agama. Kehadiran unsur fahaman ini dalam sesebuah jalur pergerakan perlulah dikenalpasti dan dibanteras seawal mungkin agar dapat membendungnya daripada disebarkan kepada umum. Hal ini merupakan sebuah cabaran yang besar kerana ianya merupakan sebuah serangan yang berbentuk ideologi sehingga boleh menggelincir ke dalam hati serta pengkaji menilai bahawa ianya berselindung disebalik "kemurnian luaran". 


\section{Rujukan}

A Rajak, R. H. (2018). Tiga sebab ICERD tidak sesuai di Malaysia. Sinar Harian. https://www.sinarharian.com.my/article/839/BERITA/Nasional/Tiga-sebabICERD-tidak-sesuai-di-Malaysia. Dicapai pada 23/4/2021.

Abdul Moqsith Ghazali (2009) Argumen Pluralisme Agama; membangun Toleransi Berbaris al-Quran, Jakarta: Kata Kita, hlm. 41-47.

Anwar, Z. (2007). Mediation the wiser path to take. New Straits Times. https://hedonese1.blogspot.com/2007/06/mediation-wiser-path-to-take.html. Dicapai pada 22/10/2021.

Azmi, A. S. (2021). Mengapa Kristian bersungguh ingin guna kalimah Allah? Ismaweb, Siti Hafidah. https://ismaweb.net/2021/03/11/mengapa-kristianbersungguh-ingin-guna-kalimah-allah/. Dicapai pada 25/10/2021.

Bernama (2021). Kabinet benarkan penganut Kristian guna kalimah Allah pada 1986. Berita Harian Online. https://www.bharian.com.my/berita/nasional/2021/03/798085/kabinetbenarkan-penganut-kristian-guna-kalimah-allah-pada-1986. Dicapai pada 28/3/2021.

Earnie Elmie Hilmi, Kamarudin Salleh, Nur Farhana Abdul Rahman (2019). "Faktorfaktor Pengaruh Penyebaran Pluralisme Agama di Malaysia." BITARA International Journal of Civilizational Studies and Human Sciences 2(1): 82.

Ezi Fadilla, Azhari Andi. (2016). "Menyikapi Pluralisme Agama Perspektif AlQur'an." Jurnal Ilmu-Ilmu Ushuluddin 17(1): 41.

Faisal Ismail, (2014). Dinamika Kerukunan antara Umat Beragama (Bandung: Remaja Rosdakarya), hlm. 17.

Fatwa Majlis Ulama Indonesia. (2005). Pluralisme, Liberalisme, DAN Sekularisme Agama. No. 7/MUNAS VII/MUI/11: hlm. 96. Dicapai pada 9/12/2020 melalui http://mui.or.id/wp-content/uploads/files/fatwa/12.-Pluralisme-Liberalismedan-Sekularisme-Agama.pdf.

Hadir, S. (2021). Kebenaran penggunaan kalimah Allah buka ruang murtad, pluralisme - Pembela. Malaysia Gazette.

https://malaysiagazette.com/2021/03/14/kebenaran-penggunaan-kalimahallah-buka-ruang-murtad-pluralisme-pembela/. Dicapai pada 30/3/2021.

Havis Aravik, Choiriyah. (2016). "Islam dan Pluralisme Agama." Jurnal Ilmu Syariah, FAI Universitas Ibn Khaldun (UIKA) BOGOR 4(2): 289.

https://accinmalaysia.wordpress.com/about. Dicapai pada 3/4/2018.

https://legal.usm.my/v3/phocadownload/laws/Perlembagaan Persekutuan.pdf.

Dicapai pada 18/3/2021.

https://projekdialog.com/about-us/. Dicapai pada 23/4/2021.

https://www.alim.org/quran/tafsir/ibn-kathir/surah/2/256/. Dicapai pada 22/10/2021. https://www.statistics.gov.my/censusatlas/images/ReligionBM.pdf. Dicapai pada $30 / 3 / 2021$.

Hussain, H. (2020). Fahaman pluralisme bertapak di Malaysia. Sinar Harian. https://www.sinarharian.com.my/article/95923/BERITA/Nasional/Fahamanpluralisme-bertapak-di-Malaysia. Dicapai pada 18/10/2021. 
Ibrahim, Haslina (2011). Dari Kepelbagaian Agama Kepada Pluralisme Agama: Sejarah Perkembangan. Seminar al-Quran dan Cabaran Pluralisme Agama: Pengajaran Masa Lalu, Keperihalan Semasa dan Hala Tuju Masa Depan, 19-20 Julai 2011, IKIM, Jalan Duta, Kuala Lumpur.

John Hick. (2005). "Religious Pluralism and Islam", internet: John Hick"s Official Website, http://www.johnhick .org.uk/article11.html. Dicapai pada 12/2/2020.

Kamali, Hashim (2011). https://www.academia.edu/12074530/ Islam_s_Religious_Pluralism_in_Context. Hlm. 716. Dicapai pada 1/12/2020. Kamus Besar Bahasa Indonesia online (KBBI) (2016), entri “isme". Dicapai pada 28/11/2020, https://kbbi.kemdikbud.go.id/

Karim, L. A. A. (2021). Penghakiman bertulis isu kalimah Allah diteliti. Berita Harian Online.

https://www.bharian.com.my/berita/nasional/2021/03/800425/penghakimanbertulis-isu-kalimah-allah-diteliti. Dicapai pada 28/3/2021.

Kartini Aboo Talib@ Khalid, S. I. (2019). "Penerimaan dan Penolakan International Convention on the Elimination of All Forms of Racial Discrimination (ICERD) dalam Kalangan Masyarakat Melayu dan Bumiputera di Malaysia." Islmaiyyat 41(2): 82.

Mohamad, K. (2019). Himpunan ICERD 812: Setahun Kebangkitan Rakyat Tolak Pengkhianat Negara. Berita Pas. https://berita.pas.org.my/himpunan-icerd-812setahun-kebangkitan-rakyat-tolak-pengkhianat-negara/. Dicapai pada 22/4/2021.

Mohd. Fauzi Hamat dan Wan Adli Wan Ramli (2007), "Pendekatan Epistemologi dalam Menangani Pluralisme Agama," dalam Konsep Asas Islam dan Hubungan Antara Agama, ed. Wan Suhaimi Wan Abdullah dan Mohd Fauzi Hamat (Kuala Lumpur: Jabatan Akidah dan Pemikiran Islam, Akademi Pengajian Islam, Universiti Malaya), 33-112.

Muhammad Fathi bin Yusof, Mohd Al-Ikhsan Ghazali, Nik Mohd Zaim Nik Abdul Rahim (2014). Cabaran Isu Perlembagaan Dan Hak Asasi Dalam Dakwah di Malaysia. Bicara Dakwah A. D. M. Muhamad Faisal Ashaari, Ahmad Irdha Mokhtar. Jabatan Pengajian Dakwah dan Kepimpinan, Fakulti Pengajian Islam, UKM, Bangi, Selangor. 15: 290-291.

Muzaffar, D. C. (2014). Understanding liberalism and religious pluralism. The Star. https://www.thestar.com.my/News/Nation/2014/11/05/Understandingliberalism-and-religious-pluralism/. Dicapai pada 21/10/2021.

Nor, M. R. M. (2013). "Aplikasi Hukum Islam Dalam Tatanan Masyarakat Global di Malaysia." Al-Risalah 13(2): 1-22.

Onions, C.T (pnyt.) (1952). Pluralisme. Dlm. The Shorter Oxfort English Dictionary on Historical Principles, hlm. 578-579. Oxford: The Clarendon Press. Dipetik dari sebuah kajian yang bertajuk "Gerakan Pluralisme Agama Di Alam Melayu”. Dicapai dari: https://www.researchgate.net/publication/342946951_Gerakan_Pluralisme_A gama Di Alam Melayu. Dicapai pada 1/12/2020.

Procter, Paul (ed.), Longman Dictionary of Contemporary English, hlm. 41. 
Prof. Dr. Hamka (2012). "Pluralisme Agama sebagai Rahmatan Lil-'Alamin.". THEOLOGIA 23(2): hlm. 435.

Rahman, Budhy Munawar (2004). Islam Pluralis, Wacana Kesetaraan Kaum Beriman, Jakarta: Sri Gunting, cetakan pertama, hlm. 39.

Sarwar, Malik Imtiyaz. (2005). "We Are Committed to Dialogue." Aliran Monthly 25, no. 6.

Tan, N. A. (2013). "Menzahirkan pluralisme dalam suasana kemelut." Projek Dialog. https://projekdialog.com/malay/menzahirkan-pluralisme-dalam-suasanakemelut/. Dicapai pada 8/4/2021.

Thoha, A. M. (2011). Mencermati Doktrin dan Ciri-ciri Fahaman Pluralisme Agama. Wacana Pemikiran dan Pembinaan Ummah 2 Peringkat Kebangsaan. Dewan Sultan Mizan, Universiti Malaysia Terengganu (UMT), Terengganu.: 8.

Wan Adli Wan Ramli. (2012). Bahaya liberalisme dan pluralisme agama terhadap akidah belia Muslim. Johor Bharu: Sekretariat menangani isu-isu akidah dan Syariah Majlis Agama Islam Negeri Johor.

Willie Jude, Goh Pei Pei. (2021). Kalimah ‘Allah’ bukan isu di Sabah, Sarawak, kata ADUN beragama Islam. Free Malaysia Today. https://www.freemalaysiatoday.com/category/bahasa/tempatan/2021/03/17/ka limah-allah-bukan-isu-di-sabah-sarawak-kata-adun-beragama-islam/. Dicapai pada 28/3/2021.

Zain, R. M. (2021). Kalimah Allah hanya untuk umat Islam - Sultan Selangor. Berita Harian Online. https:/www.bharian.com.my/berita/nasional/2021/03/799378/kalimah-allahhanya-untuk-umat-islam-sultan-selangor. Dicapai pada 31/3/2021.

Zin, Abdullah Muhammad. (2018). Pluralisme, liberal ancam institusi Islam. Berita Harian Online. https://www.bharian.com.my/rencana/muka10/2018/03/397782/pluralismeliberal-ancam-institusi-islam. Dicapai pada 18/10/2021. 